\title{
THE EFFECT OF PLUNGE DEPTH ON THE STRENGTH PROPERTIES OF FRICTION WELDED JOINTS USING THE RFSSW METHOD
}

\author{
Rafał Kluz', Andrzej Kubit' ${ }^{1}$ Dawid Wydrzyński* \\ 1 Rzeszow University of Technology, Faculty of Mechanical Engineering and Aeronautics, al. Powstańców \\ Warszawy 8, 35-959 Rzeszów, Poland \\ * Corresponding author's e-mail: dwydrzynski@prz.edu.pl
}

Received: 2017.08.18

Accepted: 2018.02.01

Published: 2018.03.01

\begin{abstract}
ASTRACT
The Refill Friction Stir Spot Welding (RFSSW) method consists of three variable process parameters: rotational speed, tool plunge time and depth. The article presents an analysis of the effects tool plunge depth on shear strength. For this purpose, samples had a shearing load applied in a device prepare for this purpose. The shear strength was determined. An analysis of the results showed that tool plunge has a large effect on the strength of the joint and the structure of the joint. Depending on the tool plunge value, three types of joint failure were observed during the static shear strength test.
\end{abstract}

Keywords: friction stir welding, joining aluminium alloys, refile friction spot stir welding

\section{INTRODUCTION}

In the field of joining metal elements, there has been a considerable improvement in the quality and increase the quantity of joining methods over the past few years. One of the more frequently used methods in recent years is Friction Stir Welding (FSW). This method is the subject of intensive research $[1,13,16,21]$. Friction Stir Spot Welding (FSSW) is one of the variants of friction welding gaining wider use in the automotive $[10,12]$ and aviation industries $[12,16]$.

The difficulties of making high quality welded joints using traditional methods have been partially overcome by FSSW technology in the automotive industry. In turn, the aviation industry demands the development of an inexpensive method of joining precipitation hardened aluminium alloys, which can ensure high joint strength while lowering the work load of the process in comparison to traditional methods. Friction stir spot welding is an alternative to resistance welding, riveting, and adhesive bonding of lightweight alloys and it has many benefits $[8,14,20,23,26,27]$.
The FSSW method can also combine materials with various properties $[2,3,5,25]$. The quality of the joint is affected by the process parameters like rotational speed, tool plunge speed, tool plunge time and tool exit time $[6,22]$. The main flaw of the FSSW method is the hole that results from the welding process that significantly weakens the strength of the joint [19]. This flaw is eliminated by a following method based on FSSW, in which the hole left from the tool is filled using different process kinematics. Refill Friction Stir Spot Welding (FRSSW) consists of welding two pieces of sheet metal using a tool made of pin and a sleeve. A diagram of the friction welding process is presented in Fig. 1. This method is based on local (spot) friction heating in the area of the joint by a rotating tool. Initially, the sleeve plunges into the material and pushes it into the place of the receded pin. Next, the sleeve recedes from the material leaving room for material extrude by the pin.

The use of a divided tool to weld in the RFSSW method changes the kinematics of creating a joint, the connection is homogenous and 


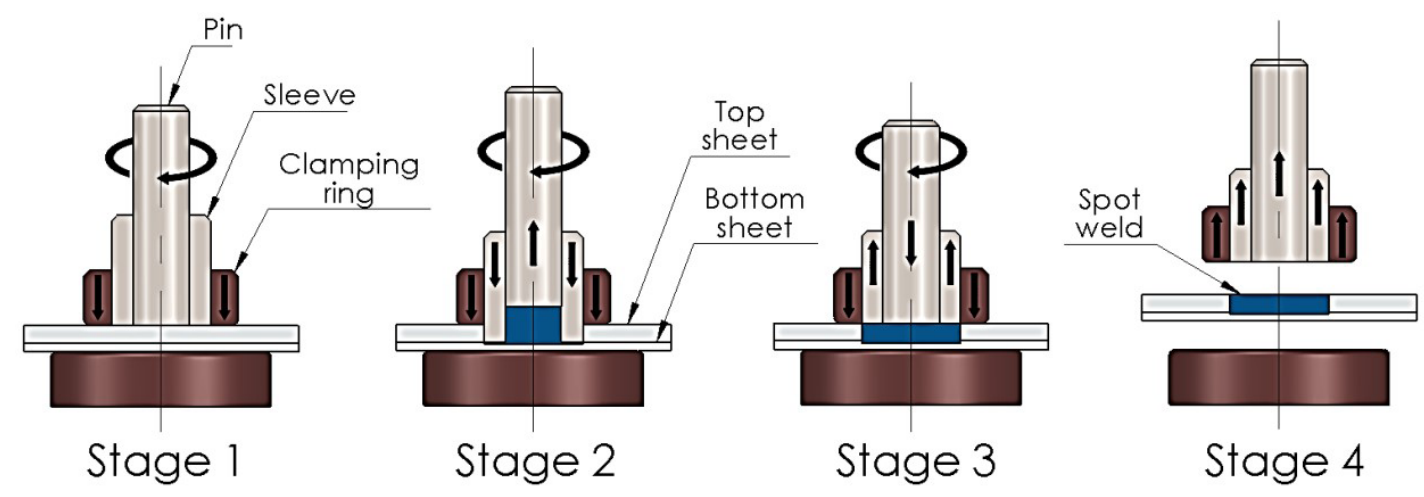

Figure 1. RFSSW process diagram

free of areas with lower densities of the alloy. The strength properties of the joint are similar to those of the parent material $[4,7,9,15]$. This is a benefit that achieves the full load carrying capacity of the joint and replaces hitherto joining methods like riveting or resistance welding. Correctly selected tool operating parameters ensure the desired effects in the form of proper joints. Incorrectly selected parameters lead to the creation of a joint of poor quality, containing multiple micro and macroscopic defects and lower load carrying capacity $[7,17]$. During the RFSSW method, the tool experiences wear very quickly, which affects the quality of the joint along the bead line. Wear is caused by substantial and repeated loading of the tool with torque, and the significant friction of the operation causes high temperatures. Both factors lead to the creation of a gap between the pin and the sleeve, which negatively affects the joint [18].

The article focuses on the analysis of tool plunge depth on the strength properties of a 7075 - T6 aluminium alloy joint. Various types of resulting failures from the static shear strength test were presented. The device used to conduct the pure shearing strength tests was also presented.

\section{MATERIALS AND EXPERIMETNAL METHOD}

The experiments were conducted using the RFSSW method on a HARMS WENDE machine with the RPS friction spot welding system (Fig. 2a). The RPS 100 friction welding system welds aluminium alloy sheet metal and approved alloys for plastic processing consisting of light metals and non-ferrous metals through the use of rotating tools (Fig. 2b). The total thickness of the welded sheet metal should not exceed $8 \mathrm{~mm}$. The feed motion is done by the friction welding tool.
The tool end is built into the grip. The RPS 100 system has an additional function of measuring force with integrated measurement box and measurement sensor near the tool [11].

The experiments were conducted on plated 7075-T6 aluminium sheet metal. The chemical composition of the alloy is presented in Table 1 . The shapes and dimensions of the samples are presented in Figure 3a.

The welded joints were made with various tool plunge depths. For this purpose, sample joints were made with a constant rotational speed of $2600 \mathrm{rpm}$ and a welding time of $\mathrm{t}=1.25 \mathrm{~s}$. The tool plunge depths ranged from $1.25 \mathrm{~mm}$ to $1.75 \mathrm{~mm}$ with a step of $0.05 \mathrm{~mm}$. In order to have repeatable joint positions, a special fixture was made (Figure 3b).

Sample with the welded joint underwent strength tests. The tensile strength test was done a ZWICK Z100 strength test machine with a feed rate of $5 \mathrm{~mm} / \mathrm{min}$. As a result of the tensile strength trials, the samples were in a complex stress state. With pure shear, there is virtually no need for calculating the structural elements of the machine. However, there are many technically significant cases where transverse forces and shearing stress have a deciding effect on the stress state. Normally the concurrently occurring stresses caused by bending are excluded. Several critical simplifying assumptions are made. As a result, simple shear is examined.

In joints of this type (Fig. 4), it is assumed that the direction of the shearing force is shared by the transverse axis of symmetry of the joint, while the distribution of shear stresses is evenly distributed though out the entire section.

The behavior of joint susceptible to shearing loads is demonstrated by a shear strength test. The results of this trail can be used to determine allowable stress, used to calculate the aforemen- 
a)

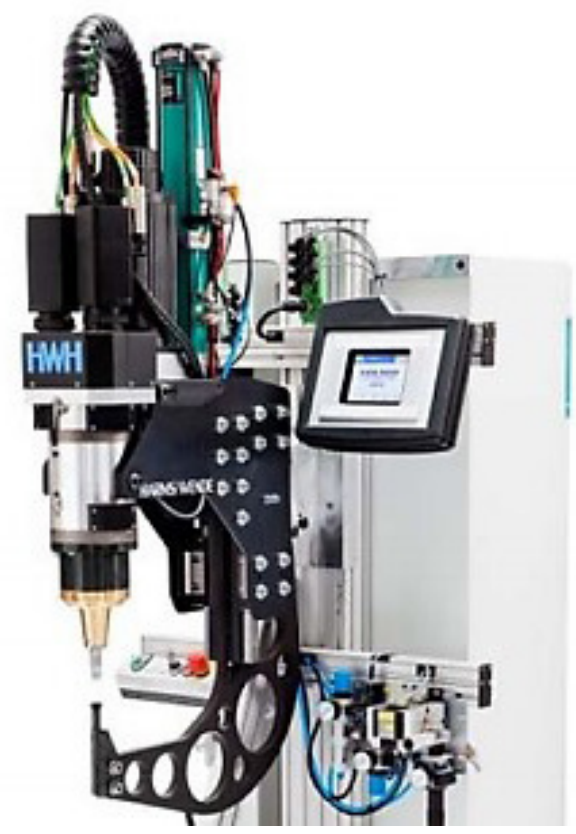

b)

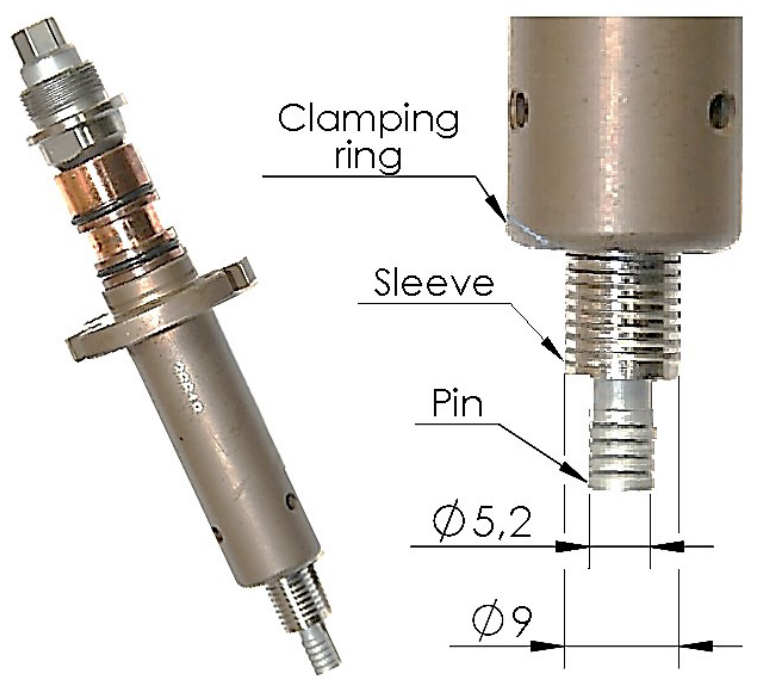

Figure 2. Friction spot welding machine made by HARMS WENDE (a), tool image and tool dimensions (b)

Table 1. Chemical composition of 7075-T6 aluminium alloy (wt.\%)

\begin{tabular}{|c|c|c|c|c|c|c|c|c|c|}
\hline $\mathrm{Si}$ & $\mathrm{Fe}$ & $\mathrm{Cu}$ & $\mathrm{Mn}$ & $\mathrm{Mg}$ & $\mathrm{Cr}$ & $\mathrm{Zn}$ & $\mathrm{Ti}$ & Other impurities & $\mathrm{Al}$ \\
\hline 0.4 & 0.5 & $1.2 \sim 2.0$ & 0.3 & $2.1 \sim 2.9$ & $0.18 \sim 0.28$ & $5.1 \sim 6.1$ & 0.3 & 0.05 & Rest \\
\hline
\end{tabular}

a)
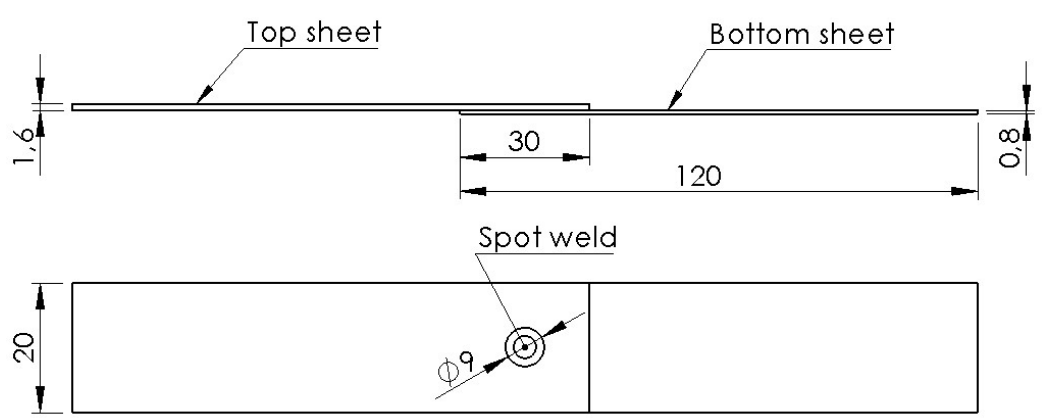

b)

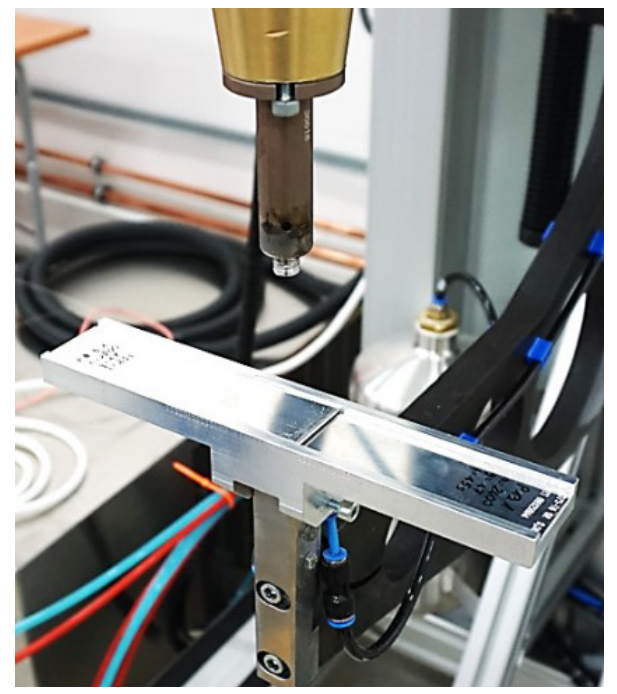

Figure 3. Dimensions of the welded joint samples (a), fixture used to position the samples (b) 


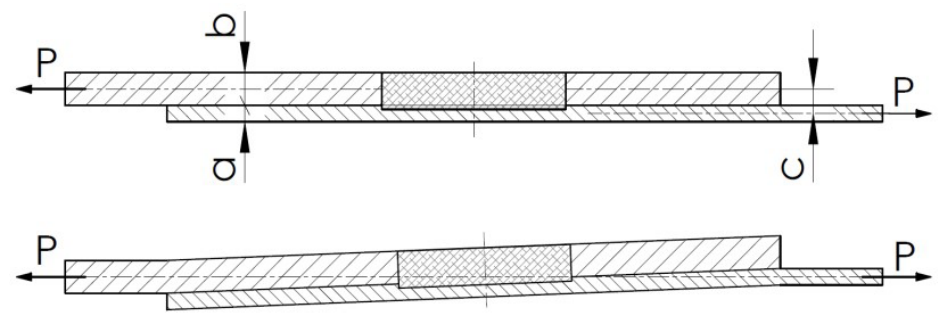

Figure 4. Example loads and joint deformation

tioned joints. Thus, this is a purely practical trial. In order to achieve pure shear in the strength test, a device ensuring this state was made (Fig. 5)

\section{RESULTS AND ANALYSIS}

Analysis of the results showed that tool plunge depth has significant effect on the load carrying capacity of the and structure of the joint. Depending on the tool plunge depth, three types of joint failure were observed during the static shear strength test (Table 2). In turn, Figure 6 presents load carrying capacities of the joints on a graph. For smaller tool plunge depth values (54$57 \%$ ), joint shearing was observed in the presence of small normal component stresses (type I). For

a)

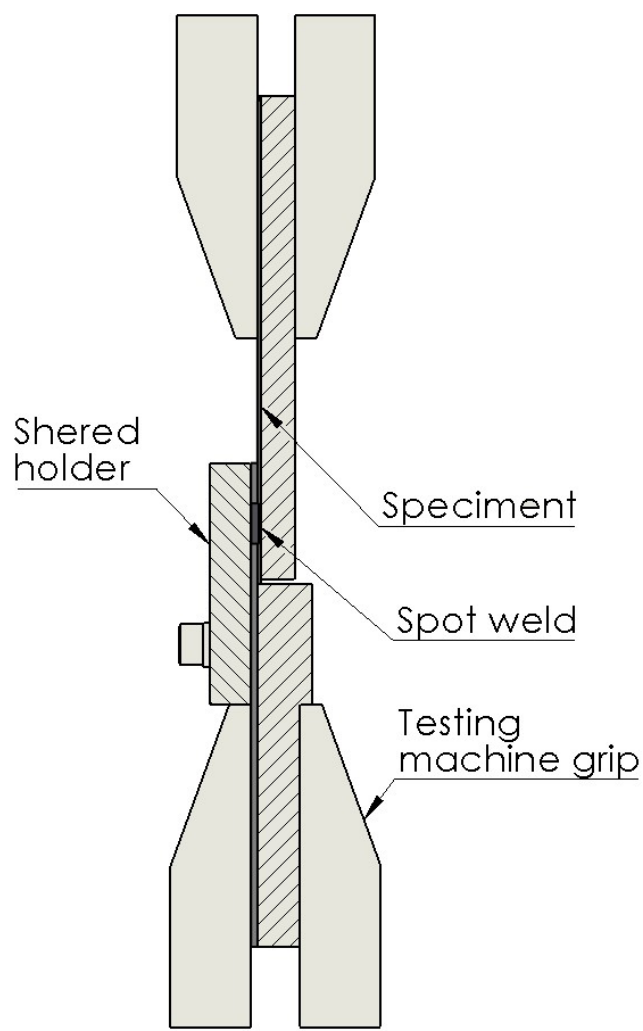

tool plunge depths of $57-61.5 \%$, partial tearing of thinner sheet was observed near the joint. This is evidence of a complex stress state and a significant role of the normal component (type II).

At plunge depths of $61.5-67 \%$, the thinner sheet was completely torn away, indicating that normal stress was prevalent in surface of the joint in the instance of failure (type III). These joints can be characterized by their slightly lower strength in comparison to joints made with less tool plunge. The cause of this should be ascribed to first and foremost the complex stress state that occurs during the static shear test. Increasing the share of normal stress causes the joint to not only experience shear but also peeling. It is impossible to directly compare the results from different tool plunge depths. In order to compare the results,

b)

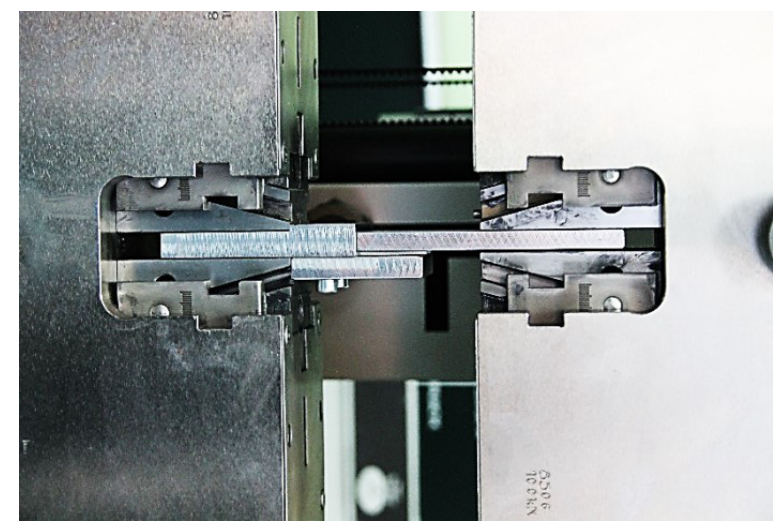

Figure 5. Device used during strength tests (a), image of the device on a strength test machine (b) 
Table 2. Types of sample failure depending on the tool plunge depth

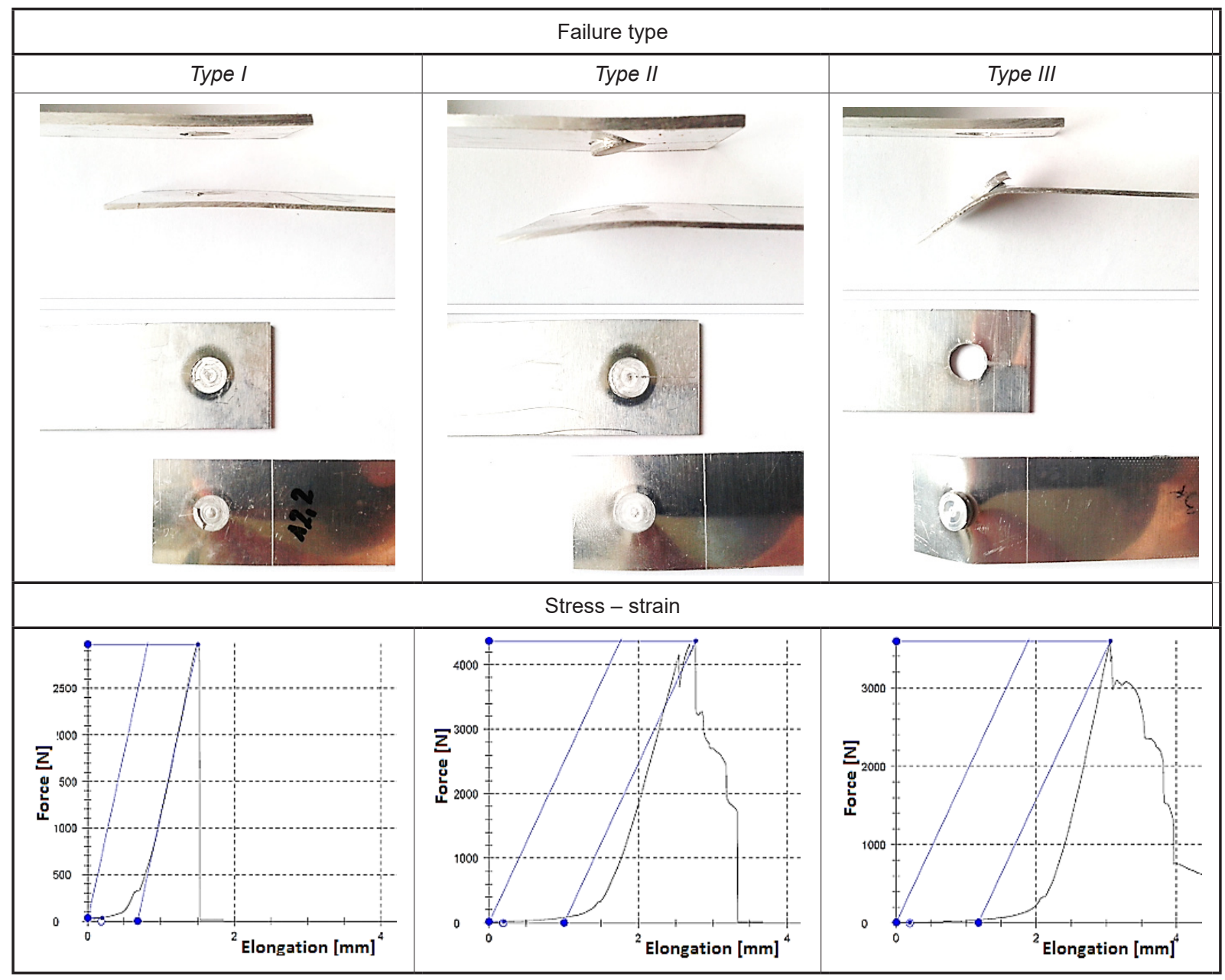

one more degree of freedom of the sample should become fixed during the static shear strength test, disenabling its bending and the prevalence of normal stress.

A shear strength test was conducted using the fixture. The fixture forced a simple stress state that resulted in values that allowed for meaningful interpretation.

The results presented in Fig. 6 unanimously state that the joints that underwent pure shearing showed that tool plunge depth had a significant effect on the load carrying capacity of the joint. Increasing the tool plunge by $30 \%$ caused the joint strength to double.

\section{CONCLUSION}

The main goal of the study was determining the effect of tool plunge depth in refill spot welding on the strength of the joint. In order to assess the strength parameters of the joints, static shear strength tests were conducted. An analysis of the results of the strength tests without forcing pure shear shows that the value tool plunge depth affects not only the load carrying capacity of the joint but also the failure type. At low tool plunge depths, the share of normal stress was not great, however an increase in plunge depth caused an incremental decrease in load carrying capacity. Using the fixture that forced pure shear allowed for meaningful results on the basis of which a constant increase load carrying capacity with tool plunge depth was noticed.

The joint load carrying capacity is not the only criterion for selecting plunge depth. An important criterion is tool wear, which with the increase of plunge depth increases the temperature of the process. Also, the process run time increases with the increase of plunge depth. The presented criteria are very important economically, as a result it is important to consider qualitative features as well as economic ones when selecting process parameters. 


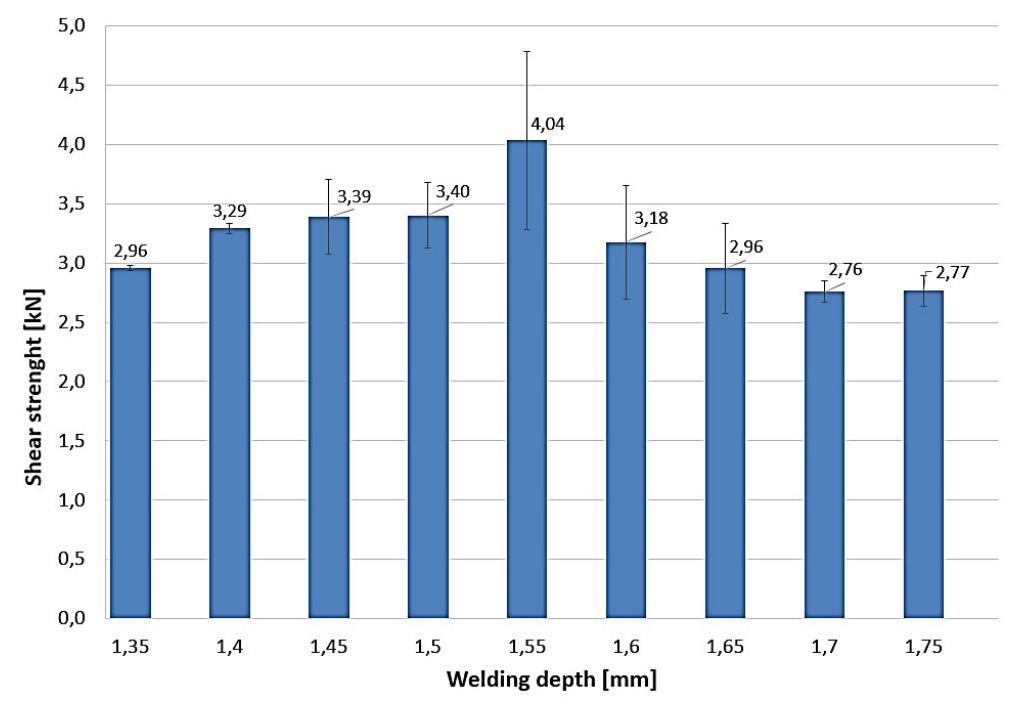

Figure 6. Joint strength - welding plunge depth graph

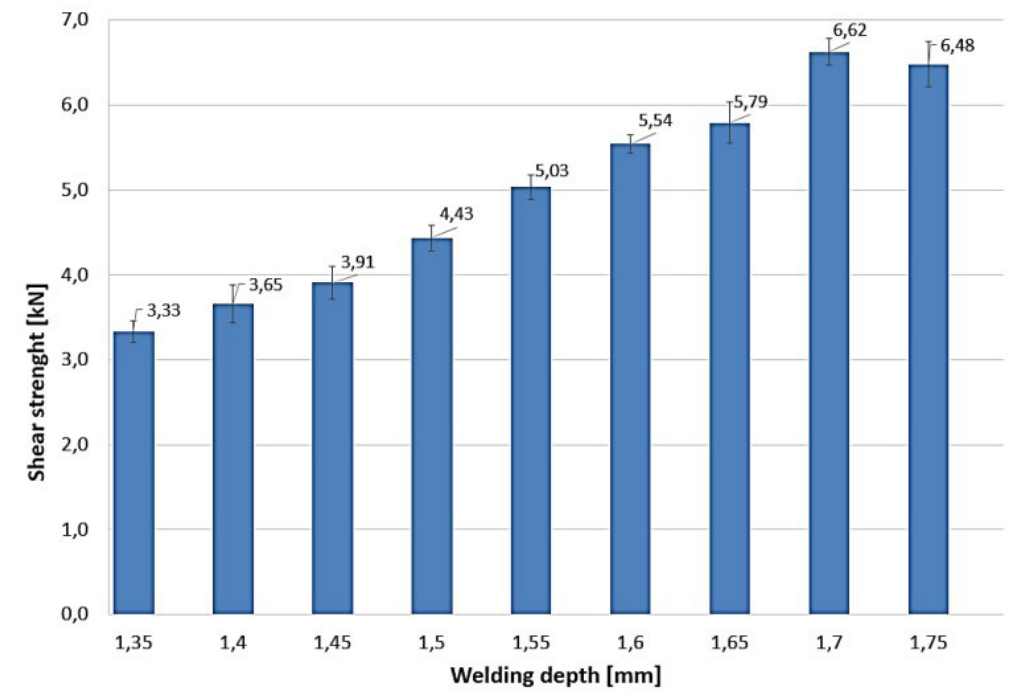

Figure 7. Joint strength - welding plunge depth graph

\section{REFERENCES}

1. Ambroziak A.: Friction welding of materials with various properties. Oficyna Wydawnicza Politechniki Wrocławskiej, 2011. (in Polish)

2. Aota K., Ikeuchi K.: Development of friction stir spot welding using rotating tool without probe and its application to low-carbon steel plates. Welding International, 2009; 23 (8): 572-580.

3. Aota K., Takahashi M., Ikeuchi K.: Friction stir spot welding of aluminum to steel by rotating tool without probe. Welding International, 2010; 24 (2): 96-104.

4. Arul S. G., Miller S. F., Kruger G. H., Pan T. Y., Mallick P. K., Shih A. J.: Experimental study of joint performance in spot friction welding of 6111T4 aluminum alloy. Science and Technology of welding and joining, 2008; 13: 629-637.
5. Baek S. W., Lee W. B., Koo J. M., Jung S. B.: A comparative evaluation of friction-welded and brazed Ti and AISI 321 stainless steel joints. Materials Science Forum, 2008; 580-582: 423-426.

6. Bozzi S., Helbert-Etter A.L., Baudin T., Klosek V., Kerbiguet J.G., Criqui B.: Influence of FSSW parameters on fracture mechanisms of 5182 aluminium welds. Journal of Materials Processing Technology, 2010, 210 (11): 1429-1435.

7. Buffa G., Fratini L., Piacentini M.: On the influence of tool path in friction stir spot welding of aluminum alloys. Journal of Materials Processing Technology, 2008, 208 (1-3): 309-317.

8. Choi D. H., Ahn B. W., Lee C. Y., Yeon Y. M., Song K. U., Jung S. B.: Effect of pin shapes on joint characteristics of friction stir spot welded AA5J32 sheet. Material Transactions 2010; 51(5): 1028-32.

9. Eggers J.: Refill Friction Stir Spot Welding 
(RFSSW). Welding aluminium accurately and consistently. HWI Weld Times, 2012: 3.

10. Hancock R.: Friction welding of aluminum cuts energy cost by $99 \%$. Welding Journal, 2004, 83: $40-45$.

11. HARMS WENDE RPS100 - Manual User 35072 $-04 \mathrm{pl}$.

12. Kenichiro M., Niels B., Livan F., Micari F., Tekkaya A. E.: Joining by plastic deformation. CIRP Annals - Manufacturing Technology, 2013; 62: 673-694.

13. Khaled T.: An outsider looks at friction stir welding. Report ANM-112N-05-06, 2005, FAA.

14. Lohwasser D. Application of Friction Stir Welding for aircraft industry. In Proceedings of the 2nd International Symposium on Friction Stir Welding, Gothenburg, Sweden, 27-29 June 2000.

15. Merzoug M., Mazari M., Berrahal L., Imad A. Parametric studies of the process of friction spot stir welding of aluminium 6060-T5 alloys. Materials and Design, 2010; 31: 3023-3028.

16. Mishra R. S., Mahoney M. W.: Friction stir welding and processing. United States of America, ASM International, 2007.

17. Mishra R. S., Zong-yi M. A.: Friction stir welding and processing. Material Science and Engineering, 2005; 50 (1-2): 1-78.

18. Montag T., Wulfsberg J., P., Hameister H., Marschner R.: Influence of Tool Wear on Quality Criteria for Refill Friction Stir Spot Welding (RFSSW) Process. Procedia CIRP, 2014; (24): 108-113.

19. Piccini J. M., Svoboda H. G.: Effect of pin length on Friction Stir Spot Welding (FSSW) of dissimilar Aluminum-steel joints. Procedia Materials Sci- ence, 2015; (9): 504-513

20. Smith C. B., Hinrichs J. F., Ruehl P. C.: Friction stir and friction stir spot welding-lean, mean, and green. Sheet metal welding conference XI, Paper 2-5, Sterling heights, MI; May 11-14, 2004.

21. Thomas W. M., Norris I. M., Staines D. G., Watts E. R.: Friction stir welding- process developments and variant techniques, The SME Summit, Oconomowoc, Milwaukee, USA, 3-4 August 2005.

22. Tier M. D., Rosendo T. S., dos Santos J. F., Huber N., Mazzaferro J. A., Mazzaferro C. P., Strohaecker T. R.: The influence of refill FSSW parameters on the microstructure and shear strength of 5042 aluminium welds. Journal of Materials Processing Technology, 2013; 213 (6): 997-1005.

23. Uematsu Y., Tokaji K.: Comparison of fatigue behaviour between resistance spot and friction stir spot welded aluminium alloy sheets. Science and Technology of welding and joining 2009; 14: 62-71.

24. Uzun H., Dalle Donne C., Argognotto A., Ghidini T., Gambaro C.: Friction Stir Welding of Dissimilar Al 6013.T4 to X5CrNi18-10 Stainless Steel. Materials and Design, 2005; 26: 41-46.

25. Watanabe T., Takayama H., Yanagisawa A.: Joining of Aluminium Alloy to Steel by Friction Stir Welding. Journal of Materials of Procesing Technology, 2006; 178: 342-349.

26. Zhang Z. H., Yang X. Q., Zhang J. L., Zhou G., Xu X. D., Zou B. L.: Effect of welding parameters on microstructure and mechanical properties of friction stir spot welded 5052 aluminum alloy. Materials and Design, 2011; 32(8-9): 4461-70.

27. Zhikang S., Xinqi Y., Zhaohua Z., Lei C., Tielong L.: Microstructure and failure mechanisms of refill friction stir spot welded 7075-T6 aluminum alloy joints. Materials and Design, 2013; 44: 476-486. 